\title{
Isomerization of Allylrhodium Intermediates During Allylations of Imines
}

Metal-Catalyzed Asymmetric Synthesis and Stereoselective Reactions

\section{Key words}

allylation

allyIrhodium

cyclic imines

Allylation of cyclic ketimines with allyltrifluoroborate via isomerization of prenylrhodium species:

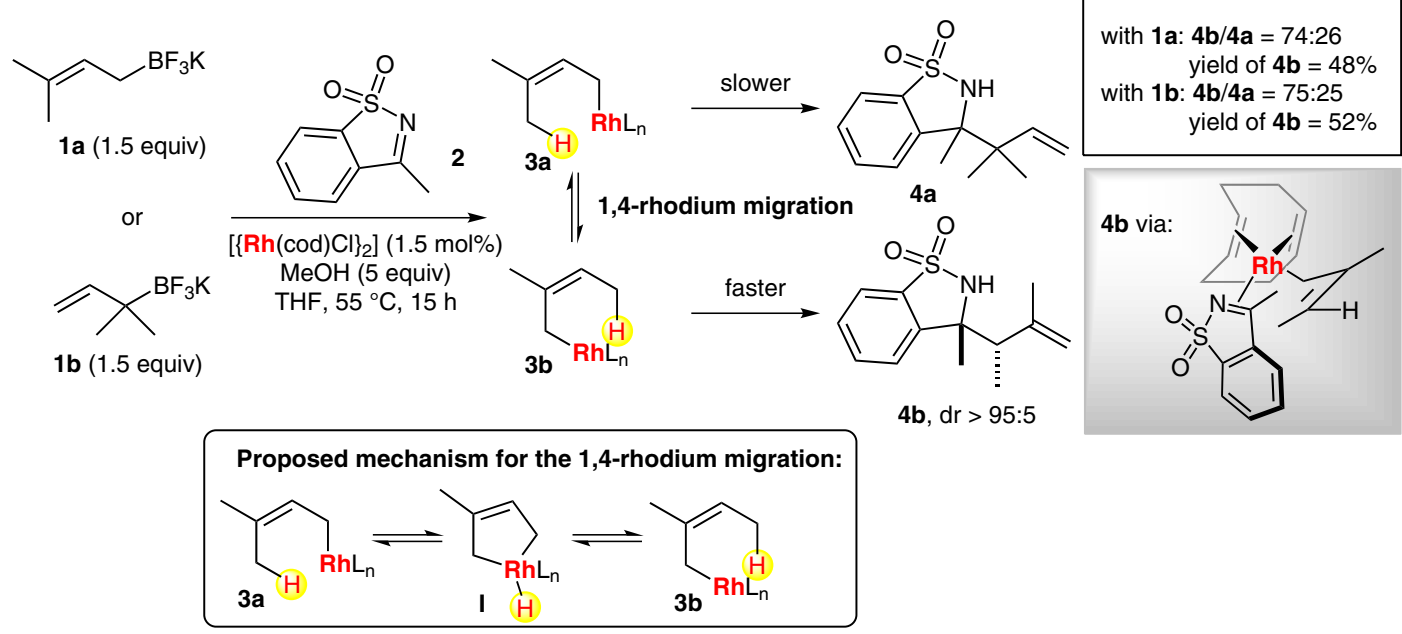

Enantioselective allylation of cyclic ketimines:<smiles>C=CC(C)(C)C1(C)NS(=O)(=O)c2ccccc21</smiles>

$4 a$

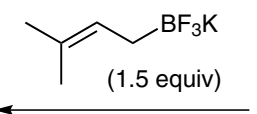<smiles>C=C(C)CC1(C)NS(=O)(=O)c2ccccc21</smiles>

$\left[\left\{\mathrm{Rh}(\mathbf{L} \mathbf{1}) \mathrm{Cl}_{2}\right](1.5 \mathrm{~mol} \%)\right.$ $\mathrm{MeOH}$ (5 equiv) $\mathrm{THF}, 55^{\circ} \mathrm{C}, 15 \mathrm{~h}$

$4 \mathbf{b} / 4 a=87: 13$ yield of $4 a+4 b=73 \%$

$4 \mathrm{~b} 62 \%$ yield (after $2^{\text {nd }}$ purification)

$d r>95: 5,97 \%$ ee
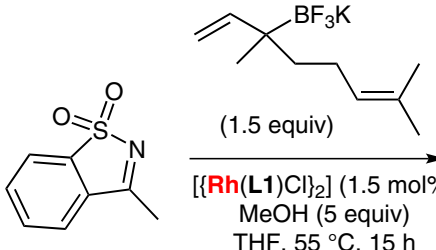

$\left[\left\{\mathrm{Rh}(\mathbf{L} 1) \mathrm{Cl}_{2}\right](1.5 \mathrm{~mol} \%)\right.$ $\mathrm{MeOH}$ (5 equiv) $\mathrm{THF}, 55^{\circ} \mathrm{C}, 15 \mathrm{~h}$

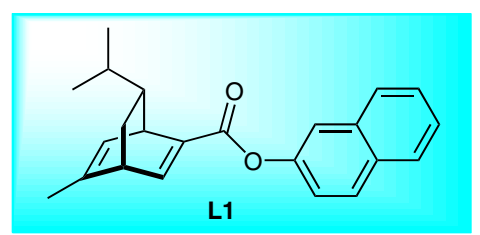

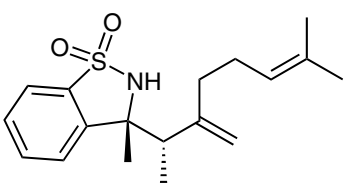

$55 \%$ yield $\mathrm{dr}>95: 5,99 \%$ ee
Significance: The authors present a 1,4-rhodium(I) migration of allylrhodium intermediates which then react with cyclic imines to yield the alIylation product with three stereochemical elements with high selectivity. Using a chiral dienerhodium catalyst the reaction can be performed enantioselectively. The significance of this work is the generation of stereochemically more complex products from simple starting material through rhodium(I)-catalyzed isomerization processes.

SYNFACTS Contributors: Hisashi Yamamoto, Biplab Maji Synfacts 2015, 11(1), $0047 \quad$ Published online: 15.12.2014 Dol: 10.1055/s-0034-1379753; Reg-No.: H15914SF
Comment: The reaction is favored in combination of two factors: 1) the steric hindrance of the initially formed allylrhodium species, and 2) the reactivity of the imine such that normal allylation is disfavored. Through the deuterium-labeling experiments it is proposed that the 1,4-rhodium(I) migration (3a $\rightarrow \mathbf{3 b}$ ) occurs by a $\mathrm{C}-\mathrm{H}$ oxidative addition-reductive elimination sequence via intermediate $\mathbf{I}$. 